\title{
Induction of callus in Cassia mimosoides
}

\author{
Yali Yang ${ }^{1,2}$, Peiting $\mathrm{He}^{1}$, Jiayi Zhang ${ }^{1}$, Lijian Jin ${ }^{1}$, Baoying Chen ${ }^{1}$, Xiaoxing Lao ${ }^{1}$, Shengyuan Zhang ${ }^{1,2}$, Lubin Zhang ${ }^{1,2}$, \\ Ming Zhai ${ }^{1, *}$, and Ying Liu $^{3, *}$ \\ ${ }^{1}$ Jiaying University, Meizhou 514031, China \\ ${ }^{2}$ Guangdong Provincial Key Laboratory of Conservation and Precision Utilization of Characteristic Agricultural Resources in \\ Mountainous Areas, Meizhou 514031, China \\ ${ }^{3}$ Department of Biotechnology, College of Coastal Agricultural Sciences, Guangdong Ocean University, Zhanjiang 524088, P.R. \\ China
}

\begin{abstract}
In this study, the young leaves of Cassia mimosoides were used as explants. On the basis of $1 / 2 \mathrm{MS}+2.0$ $\mathrm{mg} / \mathrm{L} 6-\mathrm{BA}+0.5 \mathrm{mg} / \mathrm{L}$ NAA medium, we observed the effect of adding different factors on the callus induction of C. mimosoides. The results shown that after 20 days of callus induction, it was found that the addition of $150 \mathrm{mg} / \mathrm{L}$ vitamin $\mathrm{C}$ (VC) did not affect the induction efficiency, but the growth of callus became slower; and when the concentration was higher than $150 \mathrm{mg} / \mathrm{L}$, the formation of callus would be inhibited. The induction of callus would be restrained while adding different concentrations of $\mathrm{Cu}^{2+}$ into mediums. Moreover, glutamine (Gln) had little effect on the induction of callus. Furthermore, the addition of hydrolyzed casein $(\mathrm{CH})$ would not affect the formation of callus, but the high concentration of $\mathrm{CH}$ could affect the growth status of callus. The induction efficiency of callus was severely inhibited by exogenous addition of silver nitrate $\left(\mathrm{AgNO}_{3}\right)$, and the growth status of callus was poor, and the phenomenons of early rooting had happened at the same time. The results of this study provided a theoretical basis for the subsequent optimization of bud proliferation and rooting in C. mimosoides.
\end{abstract}

\section{Introduction}

Cassia mimosoides, also known as Mimosa cassia, is a plant of the Cassia. It was originally published in the book of "Herbal for Relief of Famines" in the Ming Dynasty. It is a homology for medicine and food in China, and mainly distributed in Guangdong, Guangxi, Sichuan, Hunan and Fujian. It has an effect on indications of jaundice, heat, vomiting and diarrhea, edema in children, unfavorable urination, habitual constipation, carbuncle carbuncle, and poisonous snake bite, etc. [1]. Studies on the physical activity of $C$. mimosoides at home and abroad mainly focus on its hepatoprotective effect. The chemical composition of $C$. mimosoides includes anthraquinones, flavonoids, sterols, etc. [2]. Some previous results shown that the anthraquinone compounds in $C$. mimosoides had a strong lipase inhibitory effect, which was helpful for obesity, liver hypertrophy and hypertriglyceridemia [3, 4]. The researchers found that the water extract of $C$. mimosoides had a lipid-lowering effect and a protective effect on liver tissue [5]. Through in-depth analysis of the chemical composition of C. mimosoides, it was found that the extract of $C$. mimosoides could inhibit dimethylnitrosamine-induced liver fibrosis in rats, and it had a certain hepatoprotective activity. The mechanism might be related to the chemical components of emodin and oleanolic acid [6]. Some studies also shown that due to the high content of flavonoids and phenols in the ethyl acetate extract of $C$. mimosoides, it also had good effect on DPPH (1,1-Diphenyl-2-picrylhydrazyl Free Radical) scavenging ability and strong antioxidant activity, thus playing a role in protecting the liver [7].

In the Hakka area of Meizhou, Guangdong, China, for hundreds of years, C. mimosoides had been used as a traditional herbal medicine decoction or made into herbal tea for prevention and treatment of chronic hepatitis B, liver fibrosis, liver cirrhosis and other liver diseases. However, due to the long natural reproduction cycle and long time to obtain seeds in the natural environment, the development of the tissue culture technology of $C$. mimosoides could shorten the growth cycle, and also provide raw material support for further understanding of the basic research on the physical activity analysis and liver protection application.

\section{Materials and methods}

\subsection{Preparation of leaf explants}

The seeds of $C$. mimosoides from Yin-na mountain in meizhou were surface-sterilized for $60 \mathrm{~s}$ with $75 \%(\mathrm{v} / \mathrm{v})$ ethanol, immersed in $2 \%(\mathrm{v} / \mathrm{v})$ sodium hypochlorite $(\mathrm{NaClO})$ for $10 \mathrm{~min}$ and finally rinsed 5 times in sterile distilled water. The sterilized seeds were placed into $1 / 2$ MS medium for 14 days of culture. The young leaves were gained from aseptic seedling (less than $0.5 \times 0.5 \mathrm{~cm}$ ) with sterilized scalpels to acquire leaf explants.

\footnotetext{
* Corresponding author: yyali198622@163.com
} 


\subsection{Preparation of culture medium and culture maintenance}

1/2 MS mediums were used in the present study contained $30 \mathrm{~g} / \mathrm{L}$ sucrose and $8 \mathrm{~g} / \mathrm{L}$ agar, and adjusted to pH 5.8 with $1 \mathrm{~mol} / \mathrm{L} \mathrm{NaOH}$, and then being autoclaved at $121^{\circ} \mathrm{C}, 101 \mathrm{MPa}$ for 20 minutes. All culture treatments were kept at $22{ }^{\circ} \mathrm{C}$ under a $12 \mathrm{~h}$ photoperiod of 2000 2500 lx intensity (cool white fluorescent tubes). The relative humidity was $80 \%$.

\subsection{Different factors on callus using leaf explants of $C$. mimosoides}

For inducing callus, leaf explants were inoculated on $1 / 2$ MS medium supplemented with $2.0 \mathrm{mg} / \mathrm{L}$ 6-BA and 0.5 $\mathrm{mg} / \mathrm{L}$ NAA and other growth regulators. Different concentrations $(0,150,300$ and $450 \mathrm{mg} / \mathrm{L})$ of vitamin $\mathrm{C}$ (VC), different concentrations $(0,5,10$ and $15 \mathrm{mg} / \mathrm{L})$ of $\mathrm{CuSO}_{4}$, different concentrations $(0,10,20$ and $40 \mathrm{mg} / \mathrm{L})$ of L-Glutamine (Gln), different concentrations (0, 200, 400 and 600) of casein hydrolysate $(\mathrm{CH})$ and different concentrations $(0,50,100$ and $200 \mathrm{mg} / \mathrm{L})$ of $\mathrm{AgNO}_{3}$ were added into the mentioned above basic medium for callus induction from leaf explants of $C$. mimosoides. The percentage of callus induction was recorded after 20 days of culture.

\subsection{Evaluation of the results and data analysis}

All experiments were based on a completely randomized factorial design and repeated three times with 25-30 replicates per treatment. Induction rate of callus = (Number of explants with callus differentiation / total explants) $\times 100 \%$.

\section{Results}

\subsection{Influence of VC on callus induction from leaf explants of $C$. mimosoides}

The concentration of $\mathrm{VC}$ in the medium influenced the response of callus induction clearly (Table 1). When different concentrations of VC were added into the callus induction basal medium, the low concentration of $\mathrm{VC}$ $(150 \mathrm{mg} / \mathrm{L})$ did not affect the callus induction efficiency, but the growth of callus was slow. With the increase of $\mathrm{VC}$ concentration, the high concentration of $\mathrm{VC}$ would delay the time of callus formation in the same time (Table 1 and Figure 1).

\subsection{Effects of $\mathrm{CuSO}_{4}$ on callus induction from leaf explants of $C$. mimosoides}

After different concentrations of $\mathrm{CuSO}_{4}$ were added into the basic medium, it was found that with the gradual increase of the concentration of $\mathrm{Cu}^{2+}$, the induction efficiency of callus became lower and lower, and the growth state of callus would also be affected. When the concentration reached $15 \mathrm{mg} / \mathrm{L}$, no callus was produced in the same time, indicating that a certain concentration of $\mathrm{Cu}^{2+}$ could inhibit the formation of callus (Table 2 ).

\subsection{Results of different GIn concentrations on callus induction from leaf explants of $C$. mimosoides}

When different concentrations of Gln were added into the basic medium, it was found that although the callus induction efficiency was affected to some extent with the increase of the Gln concentrations, the callus growth conditions were good, indicating that Gln had a

Table 1. Effects of VC on callus induction of leaf explants in C. mimosoides

\begin{tabular}{ccccc}
\hline Treatment & $\begin{array}{c}\text { Concentration of } \\
\text { VC }(\mathrm{mg} / \mathrm{L})\end{array}$ & $\begin{array}{c}\text { Induction rate of } \\
\text { callus }(\%)\end{array}$ & Growth conditions & Grades \\
\hline 1 & 0 & 100 & Dense, yellow-green, medium in & +++ \\
2 & 150 & 100 & size & ++ \\
3 & 300 & 16.7 & Dense, yellow-green, very small & + \\
4 & 450 & 0 & No callus & - \\
\hline
\end{tabular}

+++ : explants were growing in good condition; ++: explants were growing in normal condition; +: explants were growing in poor condition; -: explants did not grow.

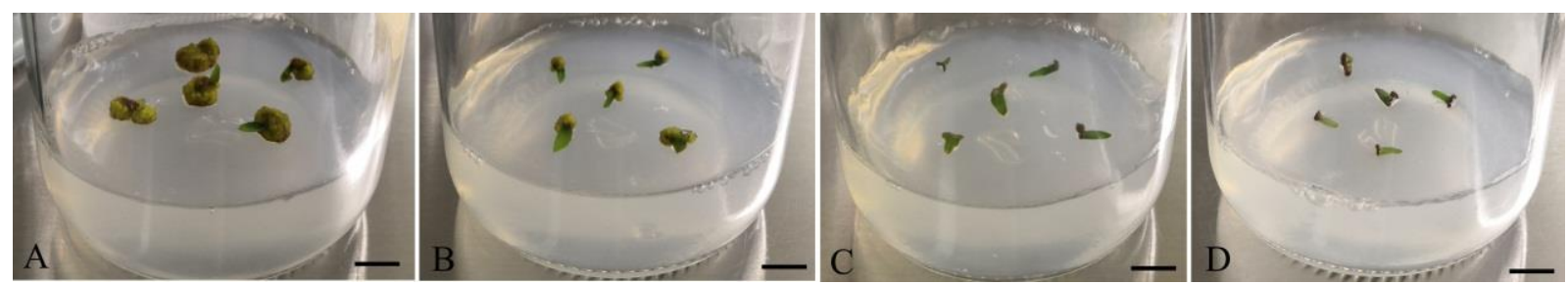

Fig. 1. Induction of callus from leaf explants of $C$. mimosoides

Leaf explants were inoculated on 1/2 MS medium supplemented with $2.0 \mathrm{mg} / \mathrm{L}$ 6-BA and $0.5 \mathrm{mg} / \mathrm{L} \mathrm{NAA}$ and (A) 0 mg/L, (B) 150 $\mathrm{mg} / \mathrm{L}$, (C) $300 \mathrm{mg} / \mathrm{L}$, (D) $450 \mathrm{mg} / \mathrm{L} \mathrm{VC}$ for 20 days (bar $=1 \mathrm{~cm}$ ).

certain effect on callus induction efficiency, but it did not

affect the callus growth state (Table 3). 


\subsection{Induction of callus from leaf explants of $C$. mimosoides by treated with $\mathrm{CH}$}

After adding different concentrations of $\mathrm{CH}$, the callus induction efficiency did not change significantly, but the growth state of callus was changed, indicating that $\mathrm{CH}$ had no effect on callus induction efficiency, but would affect the growth state of callus, and the callus became loose and grew slowly (Table 4).

\subsection{Influence of $\mathrm{AgNO}_{3}$ on callus induction from leaf explants of $C$. mimosoides}

After the addition of different concentrations of $\mathrm{AgNO}_{3}$, no obvious callus was observed and very small yellow tissue block appeared. In addition, there was root production in the medium with low concentration of $\mathrm{AgNO}_{3}$, indicating that $\mathrm{AgNO}_{3}$ would severely inhibit callus induction and promote root generation (Table 5 and Figure 2).

Table 2. Results of different $\mathrm{CuSO}_{4}$ concentrations on callus induction of leaf explants in C. mimosoides

\begin{tabular}{ccccc}
\hline Treatment & $\begin{array}{c}\text { Concentration of } \\
\mathrm{CuSO}_{4}(\mathrm{mg} / \mathrm{L})\end{array}$ & $\begin{array}{c}\text { Induction rate of } \\
\text { callus }(\%)\end{array}$ & Growth conditions & Grades \\
\hline 1 & 0 & 100 & Dense, yellow-green, medium in & +++ \\
2 & 5 & 96.67 & Dense, yellow-green, small & +++ \\
3 & 10 & 70 & Dense, yellow-green, small & ++ \\
4 & 15 & 0 & No callus & - \\
\hline
\end{tabular}

+++: explants were growing in good condition; ++: explants were growing in normal condition; +: explants were growing in poor condition; -: explants did not grow.

Table 3. Effects of Gln on callus induction of leaf explants in C. mimosoides

\begin{tabular}{|c|c|c|c|c|}
\hline Treatment & $\begin{array}{c}\text { Concentration of } \\
\text { Gln }(\mathrm{mg} / \mathrm{L})\end{array}$ & $\begin{array}{c}\text { Induction rate of } \\
\text { callus }(\%)\end{array}$ & Growth conditions & Grades \\
\hline 1 & 0 & 100 & $\begin{array}{c}\text { Dense, yellow-green, medium in } \\
\text { size }\end{array}$ & +++ \\
\hline 2 & 10 & 96.67 & $\begin{array}{l}\text { Dense, yellow-green, medium in } \\
\text { size }\end{array}$ & +++ \\
\hline 3 & 20 & 86.67 & $\begin{array}{c}\text { Dense, yellow-green, medium in } \\
\text { size }\end{array}$ & +++ \\
\hline 4 & 40 & 86.67 & $\begin{array}{c}\text { Dense, yellow-green, medium in } \\
\text { size }\end{array}$ & +++ \\
\hline
\end{tabular}

+++: explants were growing in good condition; ++: explants were growing in normal condition; +: explants were growing in poor condition; -: explants did not grow.

Table 4. Effects of $\mathrm{CH}$ concentration on callus induction of leaf explants in C. mimosoides

\begin{tabular}{ccccc}
\hline Treatment & $\begin{array}{c}\text { Concentration of } \\
\text { CH (mg/L) }\end{array}$ & $\begin{array}{c}\text { Induction rate of } \\
\text { callus }(\%)\end{array}$ & Growth conditions & Grades \\
\hline 1 & 0 & 100 & Dense, yellow-green, medium in & size \\
2 & 200 & 96.67 & Loose, yellow-green, medium in & ++ \\
3 & 400 & 96.67 & Loose, yellow-green, small & ++ \\
4 & 600 & 96.67 & Loose, yellow, very small & ++ \\
\hline
\end{tabular}

+++ : explants were growing in good condition; ++: explants were growing in normal condition; +: explants were growing in poor condition; -: explants did not grow.

Table 5. Effects of $\mathrm{AgNO}_{3}$ concentration on callus induction of leaf explants in C. mimosoides

\begin{tabular}{|c|c|c|c|c|}
\hline Treatment & $\begin{array}{c}\text { Concentration of } \\
\mathrm{AgNO}_{3}(\mathrm{mg} / \mathrm{L})\end{array}$ & $\begin{array}{c}\text { Induction rate of } \\
\text { callus }(\%)\end{array}$ & Growth conditions & Grades \\
\hline 1 & 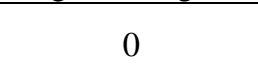 & 100 & $\begin{array}{c}\text { Dense, yellow-green, medium in } \\
\text { size }\end{array}$ & +++ \\
\hline 2 & 50 & 60 & $\begin{array}{c}\text { Compact, dark yellow-green, } \\
\text { small, long-rooted }\end{array}$ & ++ \\
\hline 3 & 100 & 6.67 & Yellow, tiny & + \\
\hline 4 & 200 & 0 & No callus & - \\
\hline
\end{tabular}


+++: explants were growing in good condition; ++: explants were growing in normal condition; +: explants were growing in poor condition; -: explants did not grow.

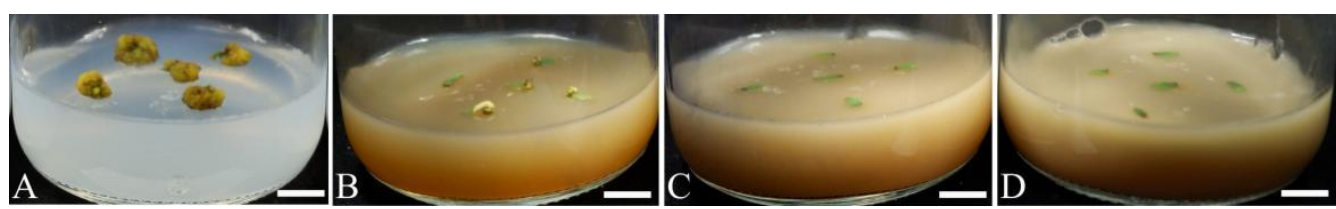

Fig. 2. Influence of $\mathrm{AgNO}_{3}$ on callus induction from leaf explants of $C$. mimosoides

Leaf explants were inoculated on 1/2 MS medium supplemented with $2.0 \mathrm{mg} / \mathrm{L} 6-\mathrm{BA}$ and $0.5 \mathrm{mg} / \mathrm{L} \mathrm{NAA}$ and (A) $0 \mathrm{mg} / \mathrm{L}$, (B) 50 $\mathrm{mg} / \mathrm{L}$, (C) $100 \mathrm{mg} / \mathrm{L}$, (D) $200 \mathrm{mg} / \mathrm{L} \mathrm{AgNO}_{3}$ for 20 days $($ bar $=1 \mathrm{~cm}$ ).

study provide a theoretical basis for the optimization of

\section{Discussion}

With the increasing demand for medicinal plants in the market, tissue culture technology of medicinal plants provides an effective means for the sustainable utilization and protection of medicinal plant resources and has a very important practical application value [8]. In plant tissue culture, many factors, including growth regulators and some trace elements, may influence the establishment of the optimal rapid propagation system. The preliminary experiment of this study found that adding $2.0 \mathrm{mg} / \mathrm{L}$ 6-BA and $0.5 \mathrm{mg} / \mathrm{L}$ NAA could effectively promote the induction of callus from leaf explants of $C$. mimosoides, and the induction rate was $100 \%$ and the growth state was good. In order to optimize the callus induction conditions, the callus induction was observed by adding different elements to the callus induction medium.

Vitamin C (VC) can not only prevent the browning of explants, but also promote the growth of callus and regeneration of adventitious buds [9, 10]. In callus induction, VC can inhibit the growth of the callus and delay the callus formation. At the same time, exogenous addition of copper, an essential element for plant growth and development, can inhibit callus formation from leaf explants of $C$. mimosoides, while some studies believe that copper can promote induction and differentiation of adventitious bud $[11,12]$, indicating that copper should not be excessive in callus induction.

Glutamine (Gln) is an organic nitrogen source additive, which can promote callus induction [13, 14], bud proliferation [15] and rooting [16]. In the present study, Gln has no significant effect on callus induction, which may be due to the low concentration of the addition, no obvious effect was observed. Hydrolyzed casein $(\mathrm{CH})$ is a kind of plant nutrition additive, which can promote the growth and differentiation of callus [17, 18]. In this study, it was found that high concentration of $\mathrm{CH}$ could inhibit the growth of callus. Silver nitrate $\left(\mathrm{AgNO}_{3}\right)$ not only promoted the growth of roots [19], but also inhibited callus browning at an appropriate concentration [20]. Furthermore, it was found that some roots were directly induced by $\mathrm{AgNO}_{3}$ before callus formation from leaf explants of $C$. mimosoides, probably due to the high concentration of $\mathrm{AgNO}_{3}$.

\section{Summary}

To sum up, different elements play different roles in callus induction of various plants. The results of this callus induction conditions of $C$. mimosoides, and also lay a foundation for subsequent bud proliferation and root generation.

\section{Acknowledgements}

This work was supported by Science and Technology Program of Guangdong Province (2020B121201013), Administration Traditional Chinese Medicine of Guangdong Province, China (No. 20202211), Promotion Program of Higher Education in Guangdong Province about Key Construction Subjects (Agricultural Resources and Environment) (Guangdong Science and education Letter [2018] NO.181), and the College Students Innovation and Entrepreneurship Training Program (S201910582106).

\section{References}

1. L R Song, X Hong, X L Ding, Z Y Zang. Dictionary of modern Chinese medicine. Beijing: people's medical publishing house, 184, 192-195(2001).

2. D F Han, C L Du, X J Wang. Chinese Journal of experimental formulae. 22(07): 78-81( 2016).

3. Subramanian S S N, Subramanian S, Sankara N S. Indian Journal of Pharmacy, 31(4): 110-111(1969).

4. Subramanian S S N. Indian Journal of Pharmacy, 32(3): 70-71(1970).

5. C P Shen, Q H Du, Y Y Zhang, G B Luo. Chinese Materia, 38(10): 2169-2171(2015).

6. J D Zhang, S P Wen, Y S Fan. Shizhen Chinese medicine, 20(11): 2879-2881(2009).

7. Z W Liu, W Kuang, C Zhang, J Zhang, Y Z Che. Food Science and Technology, 39(06): 225228(2014).

8. T T Feng, J F Guo, T L Song, X Chun, Y Wang. Bulletin of Anhui Agronomy, 25(24): 23-27(2019).

9. $\mathrm{M} \mathrm{Xu}, \mathrm{P}$ H Dai, S P Luo, Q M Gao, A Hu. Journal of xinjiang agricultural university, 37(03): 185190(2014).

10. Y X Tan. Lanzhou university of technology, 2011.

11. X D Cui, X H Su, B Y Zhang, Y G Chu,Q J Huang,W X Zhang, B Y Liu. Forestry Science Research, 25(02): 157-162(2012).

12. L Purnhauser. Cereal Research Communications, 419-423(1991). 
13. J Y Zhang, S J Jiang, Y J Xing, S P Guo, X J Guo, F Wang. Plant Research, 30(01): 22-26(2010).

14. S B Wang, S Z Huang, X Chen, J H Xu. Journal of South China Agricultural University, (01): 93(2002).

15. S M Zhou, S Y Wang, J Xu. Journal of Northern Agriculture, 44(02): 23-28 (2016).

16. Y Liu, J N Tang, C T Huang, G X Liu, S W Lin, M F Gao, D L Wu, J P Chen. Journal of Anhui Agricultural Sciences, 45(07): 125-129(2017).
17. C L Chen. Northwest agriculture and forestryuniversity, 2010.

18. Z G Li, M Gong. Journal of Yunnan Normal University, (04): 60-61(2006).

19. Y C Chen, J Wang, W J Song, D F Chen. Development of Forestry Science and Technology, (03): 97-98(2007).

20. P Q Mao, H H Li, Yuan Li, Z X Cao, M L Han, Y L Zhang. Journal of Northwest Forestry University, 33(06): 83-88(2018). 